\title{
Sleep-related movement disorders and disturbances of motor control
}

\author{
Panagiotis Bargiotas and Claudio L. Bassetti
}

\begin{abstract}
Purpose of review
Review of the literature pertaining to clinical presentation, classification, epidemiology, pathophysiology, diagnosis, and treatment of sleep-related movement disorders and disturbances of motor control.

\section{Recent findings}

Sleep-related movement disorders and disturbances of motor control are typically characterized by positive motor symptoms and are often associated with sleep disturbances and consequent daytime symptoms (e.g. fatigue, sleepiness). They often represent the first or main manifestation of underlying disorders of the central nervous system, which require specific work-up and treatment. Diverse and often combined cause factors have been identified. Although recent data provide some evidence regarding abnormal activation and/or disinhibition of motor circuits during sleep, for the majority of these disorders the pathogenetic mechanisms remain speculative. The differential diagnosis is sometimes difficult and misdiagnoses are not infrequent. The diagnosis is based on clinical and video-polysomnographic findings. Treatment of sleeprelated motor disturbances with few exceptions (e.g. restless legs/limbs syndrome) are based mainly on anecdotal reports or small series.
\end{abstract}

\section{Summary}

More state-of-the-art studies on the cause, pathophysiology, and treatment of sleep-related movement disorders and disturbances of motor control are needed.

\section{Keywords} nocturnal (sleep-related) movement disorders and disturbances of motor control, nocturnal epilepsy, parasomnias, sleep

\section{INTRODUCTION}

Rapid eye movement (REM) and non-REM (NREM) sleep are associated with profound neurophysiological and neurochemical changes in the brain, which lead to changes in the control of motor functions [1]. This explains why movement disorders and disturbances of motor control sometimes appear only or preferentially during sleep. This review will discuss literature pertaining to clinical presentation, classification, epidemiology, pathophysiology, diagnosis, and treatment of sleep-related movement disorders/ disturbances of motor control (SRMD/DMC).

\section{DEFINITION/CLASSIFICATION}

SRMD/DMC are typically characterized, with the exception of sleep paralysis, by involuntary, excessive motor activities (hyperkinesias), meaning positive motor symptoms. On rare occasions (e.g. in the context of REM sleep behavior disorder, RBD) voluntary movements may also be affected during sleep differently than during the day [2]. Interestingly, changes in muscle tone are not a relevant feature of SRMD/DMC (as it is, conversely, during daytime), with the exception of RBD.

These disorders/disturbances are commonly age-dependent [1]. Epidemiological data of the most relevant disorder/disturbances are summarized in Table 1 [3-21].

No classification system is universally accepted. Table 2 presents a possible classification of motor phenomena during sleep in terms of causes, clinical features, and sleep stages in which they occur.

Department of Neurology, Sleep-Wake-Epilepsy Center (SWEZ), University Hospital (Inselspital) and University of Bern, Bern, Switzerland

Correspondence to Dr Panagiotis Bargiotas, Department of Neurology, Inselspital, Bern University Hospital, Freiburgstrasse 18, 3010 Bern, Switzerland. Tel: +4103163230 66; fax: +4103163296 79; e-mail: panagiotis.bargiotas@insel.ch

Curr Opin Neurol 2017, 30:405-415

DOI:10.1097/WCO.0000000000000466 


\section{KEY POINTS}

- Sleep-related movement disorders/disturbances of motor control are frequent and may lead to significant sleep disturbances and consequent daytime symptoms.

- Sleep-related movement disorders/disturbances of motor control often represent the first or main manifestation of an underlying disorder of the central nervous system.

- For the majority of sleep-related movement disorders/ disturbances of motor control, pathophysiological mechanism remain speculative.

- International diagnostic or therapeutic criteria have been developed only for a few disorders (e.g. RLS).

\section{CLINICAL MANIFESTATION}

The key-features of the main SRMD/DMC are presented in the following:

\section{Hypnic jerks (sleep starts, predormital myoclonus)}

Hypnic jerks are sudden, brief contractions of the body or limbs occurring spontaneously or after a stimulus, typically at sleep onset [22]. The contracts can be accompanied by a cry and hallucinations (flashes, feeling of falling) and dreams [23]. Hypnic jerks are described as a benign movement phenomenon [24]; however, they are frequent in neurological disorders such as parkinsonian syndromes resulting in a further cause of sleep disruption [25].

Table 1. Epidemiology of sleep-related movement disorders

\begin{tabular}{|c|c|c|}
\hline $\begin{array}{l}\text { Sleep-related movement } \\
\text { disorders/disturbances } \\
\text { of motor control }\end{array}$ & $\begin{array}{l}\text { Frequency } \\
\text { in the general } \\
\text { population }\end{array}$ & Specific features \\
\hline $\begin{array}{l}\text { Sleep-related bruxism (SB) } \\
{[3,4]}\end{array}$ & $10-20 \%$ & $\begin{array}{l}\text { Highest frequency in children (14-20\%) } \\
\text { The prevalence is not associated with sex and decreases with age } \\
\text { Parental history of SB predicted SB severity }\end{array}$ \\
\hline PLMS [5] & $5-20 \%$ & $\begin{array}{l}\text { Rare below the age of } 30-40 \text { years } \\
\text { Common in sleep disordered breathing and narcolepsy } \\
\text { Very common (70-90\%) in RLS }\end{array}$ \\
\hline Sleep paralysis [6] & $5-15 \%$ & More common in narcolepsy $(50 \%)$ and in psychiatric patients $(30 \%)$ \\
\hline Sleepwalking $[7-11]$ & $5-15 \%$ & $\begin{array}{l}\text { Typically affects children (peak age } 10-12 \text { years) but it can persist or appear de novo in } \\
\text { adulthood } \\
\text { Lower frequency (1-5\%) in adults } \\
\text { The prevalence of childhood sleepwalking increases with the degree of parental history of } \\
\text { sleepwalking. } \\
\text { Among adult sleepwalkers } 13 \% \text { report an onset in adulthood }\end{array}$ \\
\hline RLS $[12,13]$ & $1-10 \%$ & $\begin{array}{l}\text { Rare in children } \\
\text { More common in uremia, iron deficiency, pregnancy (10-30\%) } \\
\text { Variable prevalence in the general population among countries }\end{array}$ \\
\hline Sleep terrors [7] & $1-5 \%$ & $\begin{array}{l}\text { Typical age-of-onset during the early childhood (peak of prevalence at } 1.5 \text { years). } \\
\text { Lower frequency in adults } \\
\text { Parental history of sleepwalking predicts the incidence of sleep terrors in children and the } \\
\text { persistent nature of sleep terrors. }\end{array}$ \\
\hline $\operatorname{RBD}[14,15]$ & $1 \%$ & $\begin{array}{l}\text { The prevalence of RBD is about } 0.5-1 \% \text { in the general population and } 2-8 \% \text { in the older } \\
\text { adult population } \\
\text { More common ( } 25-50 \%) \text { in synucleinopathies (e.g. M. Parkinson) }\end{array}$ \\
\hline $\begin{array}{l}\text { Sleep-related (nocturnal) } \\
\text { eating disorders [16] }\end{array}$ & $1 \%$ & $\begin{array}{l}\text { The age of onset is typically in adulthood, women are more frequently affected than men. } \\
\text { More common in sleepwalkers and in patients with RLS/PLMS }\end{array}$ \\
\hline Rolandic epilepsy $[17,18]$ & - & $\begin{array}{l}\text { Typically starts around the age of } 10 \text { years } \\
\text { It is thought to be among the more frequently occurring childhood epilepsy } 114 \% \text { of } \\
\text { childhood epilepsies) } \\
\text { However, definite epidemiological data are lacking } \\
\text { Prevalence between } 10-25 \% \text { in children under } 15 \text { years }\end{array}$ \\
\hline $\begin{array}{l}\text { Panayiotopoulos syndrome } \\
\text { [19] }\end{array}$ & - & $\begin{array}{l}\text { Starts around the age of } 5 \\
\text { Around } 13 \% \text { of children aged } 3-6 \text { years who have had one or more afebrile seizures }\end{array}$ \\
\hline SHE [20] & - & Definite epidemiological data are lacking (around $2 \%$ ) \\
\hline $\begin{array}{l}\text { Sleep related rhythmic } \\
\text { movement disorders [21] }\end{array}$ & - & $\begin{array}{l}\text { Typical onset in early infancy, rarely persisting in adulthood in patients with a positive family } \\
\text { history, mental retardation or associated sleep disorders } \\
\text { Familial forms have been described }\end{array}$ \\
\hline $\begin{array}{l}\text { Sleep related dissociative } \\
\text { disorders }\end{array}$ & - & typically appearing in patients with known, underlying psychiatric disorders \\
\hline
\end{tabular}

PLMS, periodic limb movements in sleep; RBD, REM sleep behavior disorder; RLS, restless legs/limbs syndrome; SHE, sleep-related hypermotor epilepsy. 


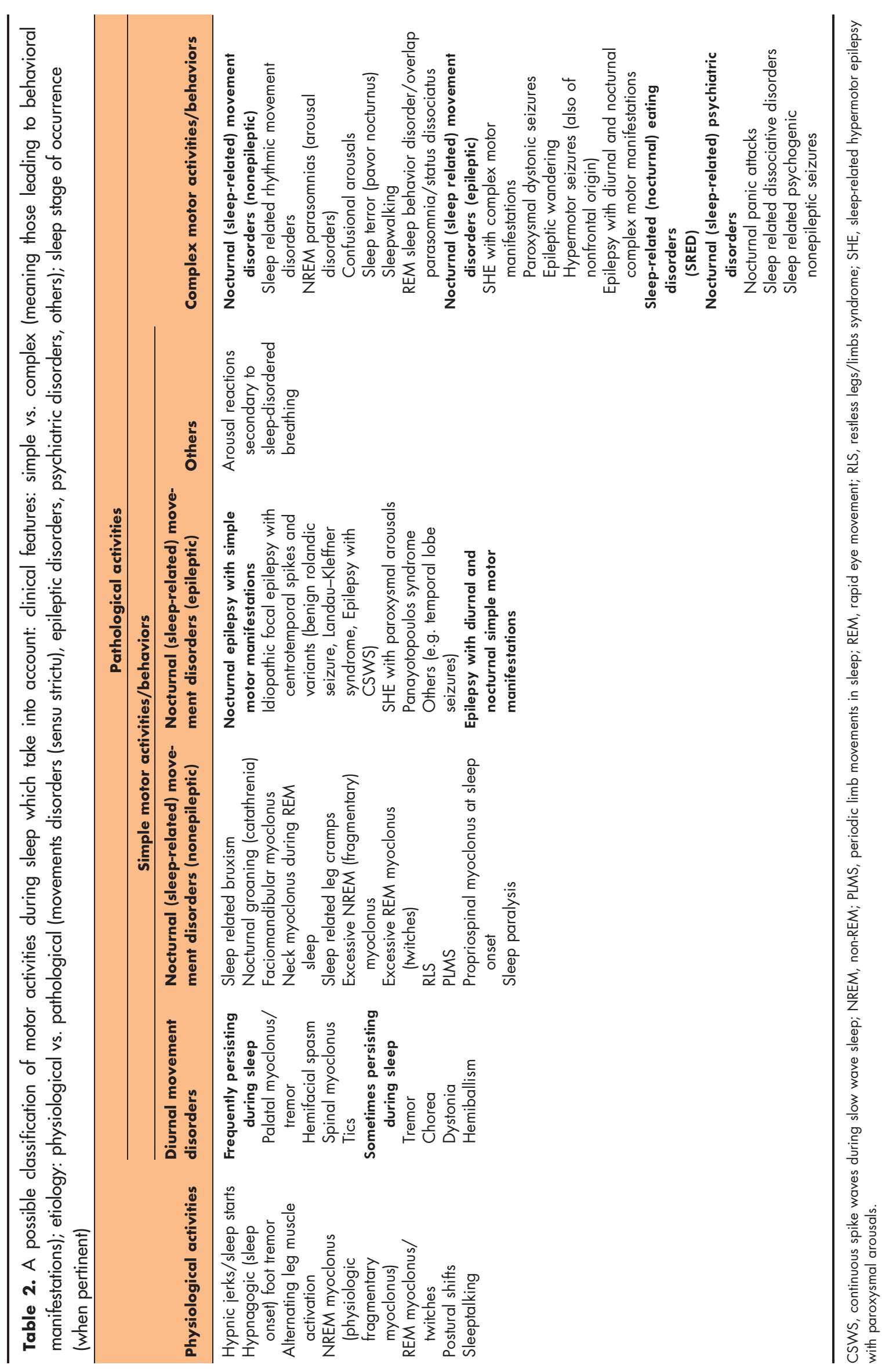


Diagnosis usually does not require any ancillary tests [26].

\section{Sleep-related bruxism}

Sleep-related bruxism consists of rhythmic tooth grinding or tapping. Typically occurs in light NREM and REM sleep. Diurnal jaw muscle discomfort is often reported, and masseter hypertrophy and alterations to the teeth and surrounding structures can be observed [27]. In a recent study, sleep-related bruxism was associated with pain and reduced sleep quality [3].

Primary and secondary forms (associated with sleep-disordered breathing, dystonia, or psychiatric disorders, e.g. anxiety, depression, and attentiondeficit/hyperactivity disorder, ADHD [28]) are known.

Diagnosis is suspected clinically and can be confirmed by typical electromyography (EMG) artefacts during video-polysomnography [26].

\section{Nocturnal groaning (catathrenia)}

It consists of repetitive expiratory respiratory (groaning, moaning) monotonous sounds occurring in clusters (mainly but not exclusively in REM sleep) and lasting for up to 30-50 s [29]. A recent study reported that the occurrence of catathrenia is associated with anatomical abnormalities of the mouth [30]. An association with (other) parasomnias is known and differential diagnosis include snoring, stridor, sleep talking, and central sleep apnea $[31,32]$. The diagnosis is made clinically.

\section{Facio-mandibular myoclonus}

This refers to nocturnal myoclonic jerks involving the jaw and facial musculature which can lead to diurnal jaw discomfort and teeth alterations [33]. The diagnosis is based on specific EMG activity of oro-facial, masticatory and cervical muscles during polysomnography.

\section{Excessive fragmentary myoclonus}

Excessive fragmentary myoclonus (EFM) refers to the presence of excessive, nonrhythmic, and nonperiodic limb twitches with no or only minimal movement effect [34]. Although EFM is described as a benign movement phenomenon [24], recent studies suggest an association with Parkinson's disease [35] and with peripheral nerve pathologies [36"]. The diagnosis is based on the presence of characteristic EMG pattern of at least $150 \mathrm{~ms}$, in at least 20 min of NREM sleep, and a rate of five EMG EFM potentials per minute, during polysomnography.

\section{Restless legs/limbs syndrome}

The restless legs/limbs syndrome (RLS) is a common, today still underdiagnosed, sensorimotor disorder. The disease can appear in childhood, its course is usually chronic with rare periods of remission. The severity of symptoms varies largely but usually enhances with age. The following international RLS diagnostic criteria have been suggested [37]:

(1) An urge to move, usually accompanied by unpleasant (or painful) sensations in the legs.

(2) The symptoms begin or worsen during periods of rest or inactivity (sitting/lying).

(3) The symptoms are partially or totally relieved by movement (walking/stretching).

(4) The symptoms are worse or occur only in the evening or at night.

Diagnosis is usually made clinically. The sensory discomfort may involve the arms (30-50\% of patients) or other body parts, as well [38]. Supportive criteria include the detection of periodic limb movements in sleep (PLMS) during polysomnography or leg actigraphy [37] (in 70-90\% of RLS patients [39]), response to dopaminergic treatment and positive family history. In addition, supportive criteria may be helpful to differentiate RLS from RLS mimics [40].

The disorder is chronic and associated with multiple comorbidities. Patients often present with insomnia, psychiatric symptoms, and occasionally with daytime excessive sleepiness and fatigue [41]. Primary and secondary forms (associated with iron deficiency, pregnancy, uremia, spinal cord diseases, parkinsonian disorders, spinocerebellar atrophies) are known $\left[13,42-45,46^{\bullet}\right]$.

\section{Periodic limb movements in sleep}

PLMS are repetitive, periodic/pseudoperiodic, stereotyped movements, usually consisting of a toe extension with a dorsiflexion of the ankle and a flexion of the knee and hip. The contractions last $0.5-10 \mathrm{~s}$, the episodes consist of at least four consecutive contractions/movements, the intervals between the episodes ranges from 5 to $90 \mathrm{~s}$ (on average 20-40s).

PLMS may result to increased arousability during the night or daytime symptoms such as fatigue, suggesting the presence of a periodic limb movements disorder (PLMD) if no other sleep disorder is diagnosed. Recently, severe PLMS have been reported to be associated with abnormal sleep behaviors, mimicking dream enacting behavior $\left[47^{\circ}\right]$ and with greater cognitive decline among nondemented individuals [48"]. The detection of PLMS 
is made by leg actigraphy and video-polysomnography.

\section{Propriospinal myoclonus at sleep onset}

Propriospinal myoclonus refers to repetitive axial jerks slowly spreading rostral and downward during the sleep-wake transition period and may leading to insomnia and falls out of the bed [49]. Differential diagnosis include Hypnic jerks, RLS, PLMS, or epileptic myoclonus [50].

\section{Sleep paralysis}

Sleep paralysis (recently reviewed by Sharpless [51]) refers to short-lasting (typically $<10$ min [52]) episodes of inability and struggle to move and speak while in the process of falling asleep or awakening [53]. Its frequency can vary from a few life events to daily episodes. Stress, excessive sleepiness, irregular sleep-wake cycle and sleep deprivation, jet lag, and uncomfortable sleeping may increase its frequency [54-56]. Anxiety, hallucinations [sensed presence; sensation of a pressure on the chest with shortness of breath (incubus); and sensation of floating/flying (out-of-body experience)] and lucid dreaming [54] are often experienced. Primary (sporadic and familial) and secondary forms (associated with narcolepsy, other sleep or psychiatric disorders $[57,58]$ ) are known. Diagnosis is usually made clinically.

\section{Sleep-related rhythmic movement disorders}

These are stereotyped, repetitive movements such as head rolling/banging, body rolling/rocking, occurring commonly at sleep onset with a frequency of $0.5-2 \mathrm{~Hz}$ and duration of seconds up to several minutes. The diagnosis is suspected clinically and made by video-polysomnography.

\section{Sleep terror (pavor nocturnus)}

It consists of spells characterized by sudden onset of fear, loud screaming, and autonomic symptoms arising from deep NREM sleep and usually lasting only few minutes. Patients are difficult to be awaken and have no recall of the episodes [26]. Frequently co-occurs with other parasomnias (e.g. sleepwalking) and in combination may lead to a consequent significant daytime sleepiness [59]. The diagnosis is suspected clinically and made by video-polysomnography.

\section{Sleepwalking (somnambulism)}

Sleepwalking refers to an ambulatory activity arising (in most cases) from deep NREM sleep $[26,60,61]$.
Patients wake up suddenly, look around with a confused stare, leave the bed, and deambulate. Movements can be repetitive and purposeless, on other occasions the appear complex and meaningful [62]. Sleepwalkers are difficult to be awakened and there is usually no recall of the episodes. Self-injuries $[63,64]$ and rarely even homicidal, filicidal, and suicidal episodes are possible [65]. Sleepwalkers have a higher frequency of other parasomnias (sleep terrors, confusional arousals, enuresis, sleeptalking, bruxism), nocturnal eating (somnophagia), and abnormal sexual behavior during sleep [66]. More recently specific reward-related personality traits [67] have been associated with sleepwalking.

Typically, sleepwalking occurs once per night (first part) and lasts several minutes. The frequency can range from few episodes in a lifetime up to several (five to six) episodes per night [9]. Sleepwalking usually appears in the context of a sporadic or familial NREM parasomnia, less frequently also in the context of a more complex NREM/REM overlap parasomnia (e.g. in neurodegenerative diseases), of a nocturnal epilepsy (epileptic wandering), or of dissociative disorders [68-70].

Diagnosis is usually made clinically. Videopolysomnography may be needed for the correct interpretation of frequently reported nocturnal deambulatory activities.

\section{Rapid eye movement sleep behavior disorder}

REM sleep behavior disorder (RBD) is a disorder characterized by an abnormal behavior arising from REM sleep which is accompanied by (oft frightening) vivid dreaming $[26,71]$. The patients 'act out their dreams' exhibiting a variety of motor activities ranging from talking and twitching of the limbs extremities to screaming, kicking, punching, grabbing, and even complex violent and nonviolent behaviors [2]. Injuries are typical and may involve the patients or their bed partners. Autonomic activation is limited/absent. Typically, RBD occurs repeatedly in the second part of the night.

RBD appears more often in elderly males and commonly in the context of synucleinopathies $[72,73])$ but also in narcolepsy [74]. Recently, motor complex behaviors, mimicking dream-enacting, have been reported in children with type 1 narcolepsy as well [75"'], further highlighting the relation between the two disorders.

The onset of RBD may precede the appearance of daytime manifestations (e.g. cognitive, motor symptoms) by up to decades [76]. Parkinsonian patients may exhibit during REM sleep/RBD in comparison to wakefulness a paradoxical improvement of speech, facial, and extremity motor control. RBD 
in parkinsonian patients has been associated with psychiatric manifestations, hallucinations, cognitive decline, and sleepwalking $[2,77]$.

Rarely, RBD occurs also in the context of a NREM/REM overlap parasomnia and its extreme form of a wake-sleep state breakdown (status dissociatus) [78-80].

International diagnostic criteria have been developed [81]. Diagnosis is confirmed by videopolysomnography documenting a loss of motor atonia, an increase of phasic muscle activity during REM sleep, and corresponding behaviors.

\section{Sleep-related epilepsy with simple motor manifestations}

The most common syndrome is that of rolandic epilepsy (also called benign epilepsy with centrotemporal spikes, BECTS), which is characterized by infrequent nocturnal (often at sleep onset or before awakening) simple, hemifacial motor seizures lasting 1-3 min. Postictal amnesia is not always present.

Panayiotopoulos syndrome refers to an idiopathic epileptic syndrome with (typically nocturnal) short episodes of disturbed autonomic functions (e.g. nausea, retching, vomiting) and occasionally with syncope-like epileptic seizures [82].

Others: typically temporal lobe epilepsy and occasionally sleep-related hypermotor epilepsy (SHE) with paroxysmal arousals, may manifest with nocturnal simple motor manifestations $[33,83]$.

\section{Sleep-related epilepsy with complex motor manifestations}

SHE and hypermotor seizures of nonfrontal origin (e.g. insula, temporal, or occipital cortex) are characterized by a wide spectrum of stereotyped manifestations, mostly occurring during NREM sleep. The short-lasting (10-30s) episodes present a sudden onset of motor behaviors including repetitive patterns (hand clenching, arm raising/lowering, knee bending), more complex patterns (hypermotor/ hyperkinetic seizure) such as body rocking, kicking, pedaling, hitting, boxing, screaming, and episodic nocturnal/epileptic wandering, and occasionally asymmetric tonic posturing of the extremities (nocturnal paroxysmal dystonic seizures) [33,84-88]. The amnesia can be incomplete.

For the diagnosis of SHE, a video-polysomnography is needed. The features differentiating SHE from motor parasomnias and dissociative sleep related disorders are: several attacks per night at any time during the night, brief duration of the attacks, and stereotyped motor pattern $[85,86]$.

\section{Nocturnal sleep-related eating disorders}

Nocturnal sleep-related eating disorders (NSRED) present with an evening hyperphagia and/or nocturnal awakening and ingestion of food. Awareness of the night eating is inconstant/absent. When awareness is present the term of night eating syndrome (NES) is preferred.

NSRED comorbidities include depression, insomnia, RLS, and sleepwalking $[16,89]$. Recent studies reported associations of nocturnal eating with anxiety and obsessive-compulsive symptoms $[90,91]$.

\section{Sleep-related dissociative disorders/ psychogenic nonepileptic seizures}

These disorders manifest typically after awakening from sleep with nocturnal episode of complex motor behaviors (e.g. vocalization, screaming, crying, deambulation/sleepwalking, violence, self-mutilation) and are common in patients with known, underlying psychiatric disorders [70,92]. Episodes may last for several minutes up to hours. Amnesia is typically present for the episodes. A coexistence of 'true' epileptic seizures and parasomnias in a single patient is possible and can complicate the diagnosis. In these cases video-polysomnography/telemetry is necessary.

\section{ETIOLOGY}

Several etiologic factors, not uncommonly in combination, of SRMD/DMC have been identified, suggesting for some of them an underlying continuous spectrum of disorder (for RLS reviewed by Trenkwalder et al. [93"]).

Genetic factors are known to be relevant for RLS [reviewed recently by Winkelman et al. [94"]), sleepwalking (positive family history in $25-50 \%$ ), bruxism, SHE (25\% of cases), rolandic epilepsy $[84,95,96]$, and for RBD $[97,98]$ including the susceptibility of individuals with RBD to develop synucleinopathies $[99,100]$ (although negative for APOE e4 allele [101]). More recent studies reported an association of PLMS [102] and of sleep paralysis [103] with specific singlenucleotide polymorphisms.

Neurodegeneration probable RBD is associated with neurodegenerative disease markers such as hyposmia and nonmotor symptoms [15] and over $50 \%$ of patients with idiopathic RBD develop within 5-10 years a neurodegenerative parkinsonian disorder (typically a synucleinopathy) [72,73,104", 105"',106",107].

Focal brain damage is mainly related to nocturnal epilepsy (e.g. in the context of cortical dysplasia [108]), RBD (limbic encephalitis, brainstem stroke, 
demyelinating disorders $[109,110])$, and RLS (e.g. spinal cord demyelination, subcortical stroke).

Psychiatric factors/disorders is an underlying stress or psychiatric disorder is often found in (particularly adult) patients with sleepwalking, bruxism, sleep-related dissociative disorders, nocturnal eating disorder, and sleep paralysis [111-113]. A number of studies highlighted the association of RLS with psychiatric disturbances (recently reviewed by Mackie et al. [114]) mainly with depression and anxiety and with ADHD [115]. Interestingly, patients with RLS with augmentation are at high risk of developing impulsive behavior, suggesting that impulse control disorder and augmentation may share a common pathophysiology [116"'].

Drug effects: Benzodiazepine may trigger/ exacerbate sleepwalking, occasionally also NSRED; antidepressants may exacerbate RBD, RLS, sleepwalking, and bruxism; neuroleptics can exacerbate RLS and bruxism; dopaminergic drugs may trigger/aggravate NSRED and bruxism $[117,118]$.

Others: Alcohol has been shown to exacerbate RBD, PLMS, bruxism, and sleepwalking [119]. A deficient iron transport/metabolism and content, recently highlighted also in quantitative magnetic susceptibility [46"], may underlie RLS.

\section{PATHOPHYSIOLOGY}

Motor control requires afferent, integrating, and efferent systems involving the spinal cord, the brainstem, the cerebellum, the basal ganglia, and the cerebral cortex.

Nocturnal/sleep-related motor manifestations arise from a disruption of such mechanisms, often in form of the abnormal activation and/or disinhibition of motor circuits. However, he exact

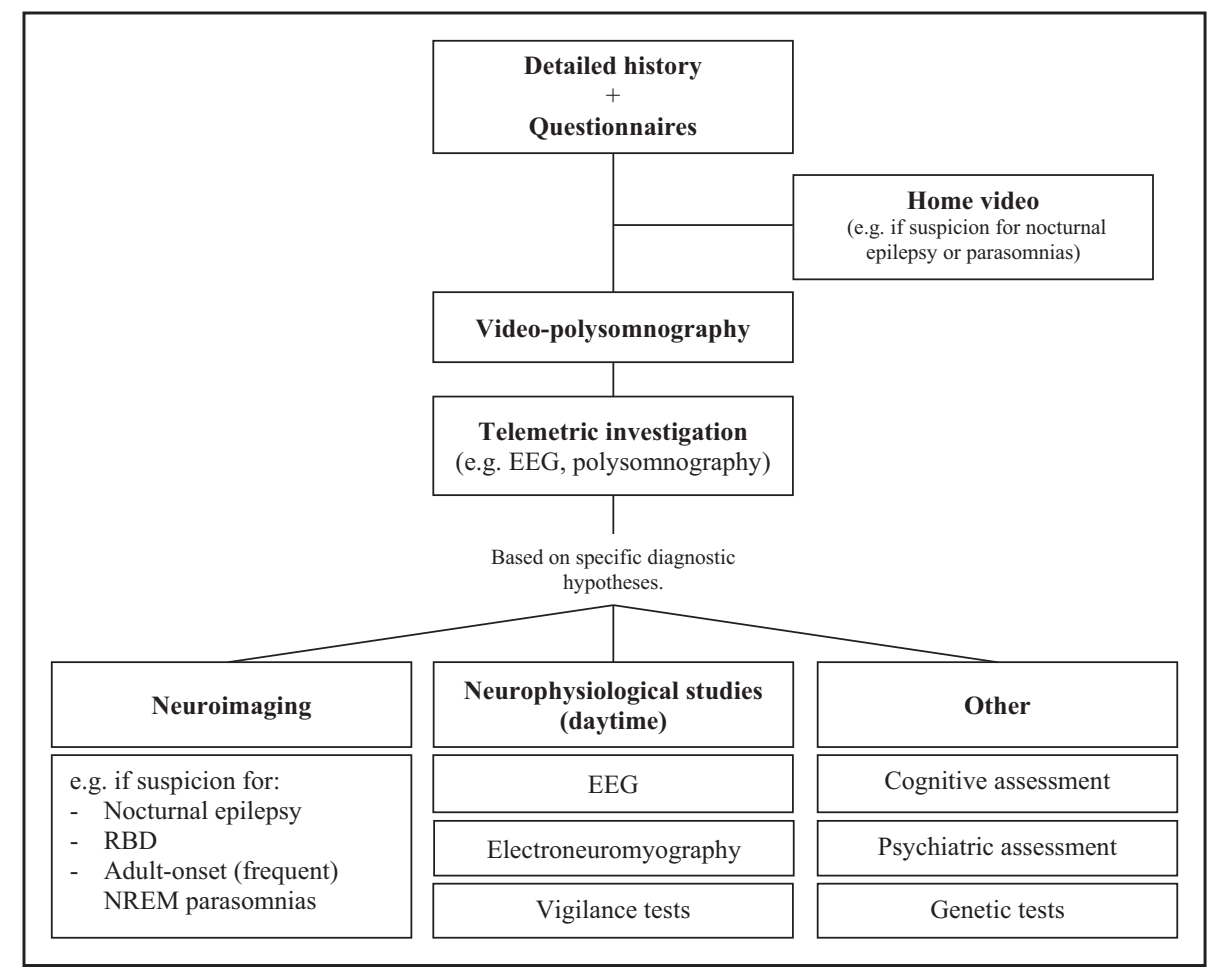

FIGURE 1. The flowchart shows important steps and tools for the diagnostic work-up of sleep-related movement disorders and motor control disturbances. Detailed history: whenever possible including an interview with bed partners. International diagnostic criteria have been develop only for a few disorders including RLS and RBD [37,81]. Questionnaires: Few scales have been suggested to estimate the severity of some of these disorders (e.g. RLS and RBD), others to differentiate between epileptic and nonepileptic disorders $[77,130,131]$. Home video: it may be helpful as a first step before performing more sleep or telemetric investigations, especially if suspicion for nocturnal epilepsy or parasomnias. Video-polysomnography including multiple EEG and EMG derivations: In some situations (e.g. NREM parasomnias, nocturnal epilepsy) sleep deprivation may be used to trigger motor events. Neuroimaging: it should be considered especially in patients with suspicious nocturnal epilepsy, REM sleep behavior disorder (RBD) and adult-onset (frequent) NREM parasomnias. Based on specific diagnostic hypotheses specific diagnostic including EEG (e.g. epilepsy, adult-onset parasomnias), daytime neurophysiological studies (e.g. sleepwalking, RBD) genetic tests (e.g. epilepsy), detailed cognitive (e.g. RBD) and psychiatric (e.g. sleep related dissociative disorders, nocturnal eating disorder, sleep paralysis, RLS) assessments, should be considered. 
contribution of afferent or efferent systems (and corresponding neurotransmitters) in these disorders remains speculative $[60,120]$. In sleepwalking, autosomal dominant SHE, and nocturnal (sleep-related) panic attacks a primary dysfunction of ascending, activating systems may prevail $[60,121]$. In addition, in RBD a primary dysfunction of descending, inhibitory systems is currently favored [120]. In most situations, a dysfunction in both systems is probably involved [77].

In sleep paralysis, emerging hypotheses regarding the pathophysiology of the commonly reported 'bedroom intruder' hallucinations implicate the mirror neurons system and interaction between several brain region, mainly the prefrontal cortex and the sensory feedback [122].

In RLS, increasing data support the notion of a complex network disorder, involving primarily the brain iron content reduction and then the dysfunction of dopaminergic pathways in nigrostriatal and mesolimbic networks [123].

Complex nocturnal/sleep-related motor manifestations/behaviors are thought to arise from the abnormal (nonepileptic/epileptic) activation of innate (genetically determined) or learned motor patterns (central pattern generators) that are essential for survival $[124,125]$. The term of 'state dissociation' has been used to describe the coexistence of abnormally activated brain areas with others that exhibits features of normal sleep [126]. Such a dissociation has been documented in few patients with parasomnias and sleep-related epilepsy by means of neuroimaging and neurophysiological methods $[121,127,128]$.

\section{DIAGNOSTIC WORK UP}

The etiological differential diagnosis between SRMD/DMC is sometimes difficult [84] and coexistence in a single patient (e.g. nocturnal seizures and parasomnias) is frequent $[33,129]$. In addition, the clinical phenomenology can be observed in the context of sleep disorders of different etiology.

International diagnostic criteria have been developed only for RLS and RBD [37,81]. Few scales have been suggested to estimate the severity of some of these disorders (e.g. RLS and RBD), or to differentiate between disorders $[77,130,131]$.

A diagnostic work-up of SRMD/DMC is presented in Fig. 1.

\section{TREATMENT}

For most SRMD/DMC, only anecdotal reports or small series have been published on treatment. International treatment guidelines have been

Table 3. General principles of treatment for sleep related movement disorders

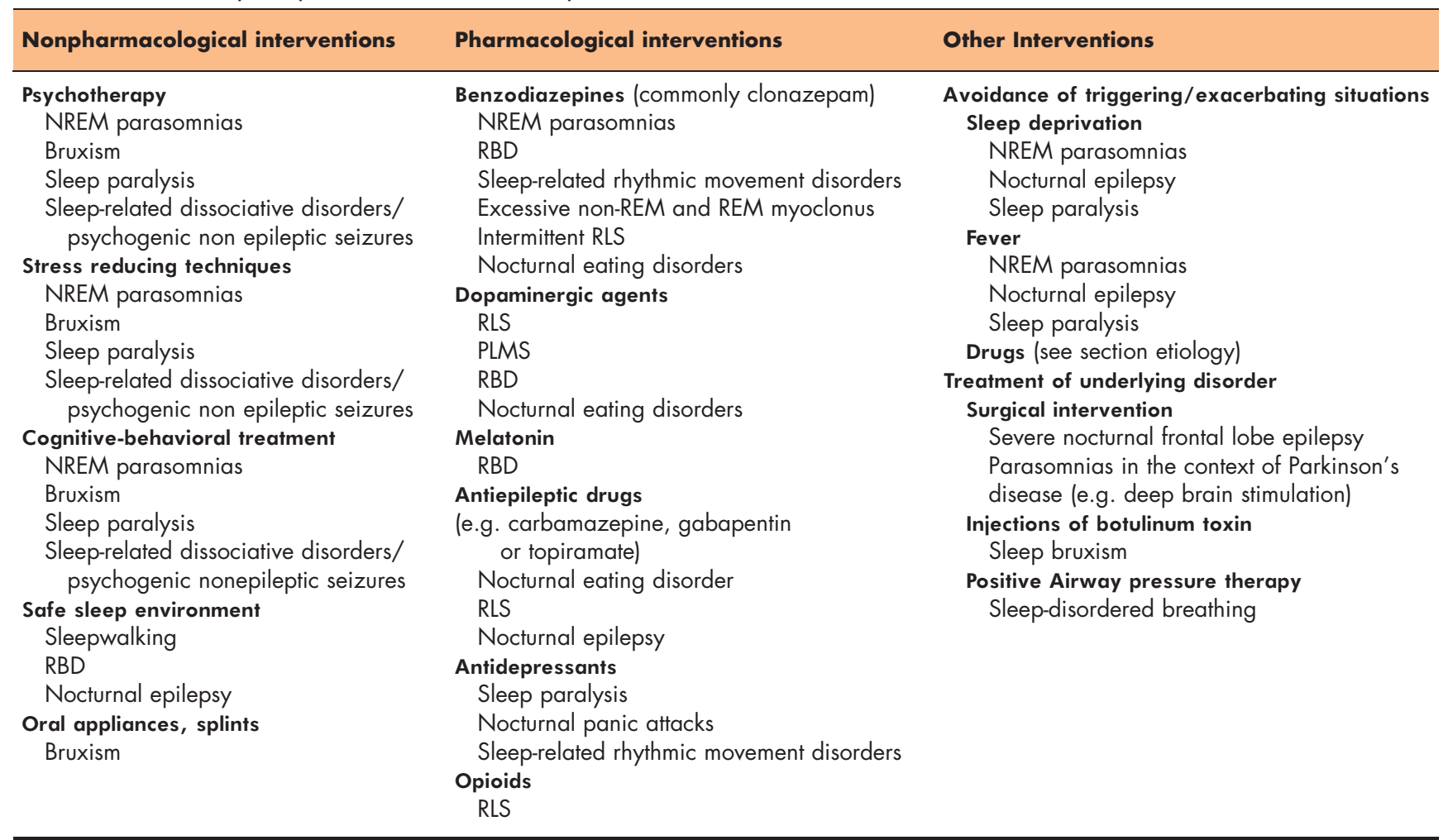

NREM, non-REM; PLMS, periodic limb movements in sleep; RBD, REM sleep behavior disorder; REM, rapid eye movement; RLS, restless legs/limbs syndrome. 
published only for RLS [132]. General principles of treatment are presented in Table 3.

\section{CONCLUSION}

SRMD/DMC are frequent and may lead to significant sleep disturbances (e.g. sleep fragmentation/ insomnia, sleep-associated injuries/violence) and consequent daytime symptoms (e.g. fatigue, sleepiness). In addition, they can represent the first or main manifestation of an underlying disorder of the central nervous system (e.g. epilepsy, neurodegenerative disease) which requires specific work-up and treatment. In most SRMD/DMC, the pathogenetic mechanisms remain speculative. Several etiologic factors have been identified, not uncommonly in combination however the differential diagnosis is sometimes difficult. International diagnostic or therapeutic criteria have been developed only for a few disorders (e.g. RLS). More state-of-the-art studies on the treatment of these disorders are needed.

\section{Acknowledgements}

None.

\section{Financial support and sponsorship}

P.B. received a grant from the University Hospital Bern, Inselspital (Insel-Grant), Bern, Switzerland.

C.B. has received honoraria for consultancy, lectures, and board memberships from the following institutions/companies: Jazz, Servier, UCB, Zambon. His research is currently supported by grants of the following institutions/companies: Swiss National Science Foundation (SNF), ResMed, Respironics, Vifor Pharma, UCB Pharma, Schweizerische Herzstiftung, Tropos Stiftung, Parkinson Schweiz.

\section{Conflicts of interest}

The authors have no conflicts of interest.

\section{REFERENCES AND RECOMMENDED \\ READING}

Papers of particular interest, published within the annual period of review, have been highlighted as:

- of special interest

- of outstanding interest

1. Chokroverty S, Allen RP, Walters AS, et al. Sleep and movement disorders. Oxford University Press; 2013.

2. De Cock Cochen VC, Vidaihlet M, Leu S, et al. Restoration of normal motor control in Parkinson's disease during REM sleep. Brain 2007; 130:450456.

3. Khoury S, Carra MC, Huynh N, et al. Sleep bruxism-tooth grinding prevalence, characteristics and familial aggregation: a large cross-sectional survey and polysomnographic validation. Sleep 2016; 39:2049-2056.

4. Bader G, Lavigne G. Sleep bruxism; an overview of an oromandibular sleep movement disorder. REVIEW ARTICLE. Sleep Med Rev 2000; 4:27-43.

5. Ohayon MM, Roth T. Prevalence of restless legs syndrome and periodic limb movement disorder in the general population. J Psychosom Res 2002; 53:547-554.
6. Sharpless BA, Barber JP. Lifetime prevalence rates of sleep paralysis: a systematic review. Sleep Med Rev 2011; 15:311-315.

7. Petit D, Pennestri MH, Paquet J, et al. Childhood sleepwalking and sleep terrors: a longitudinal study of prevalence and familial aggregation. JAMA Pediatr 2015; 169:653-658.

8. Hublin C, Kaprio J, Partinen M, et al. Prevalence and genetics of sleepwalking: a population-based twin study. Neurology 1997; 48:177-181.

9. Kavey NB, Whyte J, Resor SR, et al. Somnambulism in adults. Neurology 1990; 40:749-752

10. Hublin C, Kaprio J. Genetic aspects and genetic epidemiology of parasomnias. Sleep Med Rev 2003; 7:413-421.

11. Ohayon MM, Mahowald MW, Dauvilliers $Y$, et al. Prevalence and comorbidity of nocturnal wandering in the U.S. adult general population. Neurology 2012; 78:1583-1589.

12. Rothdach AJ, Trenkwalder C, Haberstock J, et al. Prevalence and risk factors of RLS in an elderly population: the MEMO study. Memory and Morbidity in Augsburg Elderly. Neurology 2000; 54:1064-1068.

13. Hübner A, Krafft $A$, Gadient $S$, et al. Characteristics and determinants of restless legs syndrome in pregnancy: a prospective study. Neurology 2013; $80: 738-742$.

14. Kang SH, Yoon IY, Lee SD, et al. REM sleep behavior disorder in the Korean elderly population: prevalence and clinical characteristics. Sleep 2013; 36:1147-1152.

15. Mahlknecht $P$, Seppi $K$, Frauscher $B$, et al. Probable RBD and association with neurodegenerative disease markers: a population-based study. Mov Disord 2015; 30:1417-1421.

16. Auger RR. Sleep-related eating disorders. Psychiatry 2006; 3:64-70.

17. Cavazzuti GB. Epidemiology of different types of epilepsy in school age children of Modena, Italy. Epilepsia 1980; 21:57-62.

18. Sidenvall R, Forsgren L, Blomquist $H K$, et al. A community-based prospective incidence study of epileptic seizures in children. Acta Paediatr 1993; 82:6065.

19. Panayiotopoulos CP. Vomiting as an ictal manifestation of epileptic seizures and syndromes. J Neurol Neurosurg Psychiatry 1988; 51:1448-1451.

20. Vignatelli L, Bisulli F, Giovannini G, et al. Prevalence of nocturnal frontal lobe epilepsy in the adult population of Bologna and Modena, Emilia-Romagna region, Italy. Sleep 2015; 38:479-485.

21. Mayer G, Tracik F, Wilde F. Rhythmic movement disorder revisited. J Sleep Res 2000; 9 (Suppl 1):127.

22. Oswald I. Sudden bodily jerks on falling asleep. Brain 1959; 82:92-103.

23. Frenette E, Guilleminault C. Nonepileptic paroxysmal sleep disorders. Handb Clin Neurol 2013; 112:857-860.

24. American Academy of Sleep Medicine. International classification of sleep disorders. 3rd ed. Darien, IL: American Academy of Sleep Medicine; 2014.

25. Chiaro G, Calandra-Buonaura G, Sambati L, et al. Hypnic jerks are an underestimated sleep motor phenomenon in patients with parkinsonism. A video-polysomnographic and neurophysiological study. Sleep Med 2016; 26:37-44.

26. American Academy of Sleep Medicine. International classification of sleep disorders. 3rd ed. Darien, IL: American Academy of Sleep Medicine; 2014

27. Rugh JD, Harlan J. Nocturnal bruxism and temporomandibular disorders. Adv Neurol 1988; 49:329-341.

28. Kato T, Lavigne GL. Sleep bruxism: a sleep-related movement disorder. Sleep Med Clin 2010; 5:9-53.

29. De Roeck J, van Hoof $E$, Cluydts R. Sleep-related expiratory groaning: a case report. Sleep 1983; 12:237.

30. Hao Z, Xu L, Zhang J, et al. Anatomical characteristics of catathrenia (nocturnal groaning) in upper airway and orofacial structures. Sleep Breath 2016; 20:103-111.

31. Guilleminault $C$, Hagen CC, Khaja AM. Catathrenia is not expiratory snoring. Sleep 2008; 31:774-775.

32. Guilleminault C, Hagen CC, Khaja AM. Catathrenia: parasomnia or uncommon feature of sleep disordered breathing? Sleep 2008; 31:132-139.

33. Tinuper $P$, Provini F, Bisulli F, et al. Movement disorders in sleep: Guidelines differentiating epielptic from nonepileptic motro phenomena arising from sleep. Sleep Med Rev 2007; 11:255-267.

34. Broughton R, Tolentino MA, Krelina M. Excessive fragmentary myoclonus in NREM sleep: a report of 38 cases. Electroencephalogr Clin Neurophysiol $1985 ; 61: 123-133$

35. Sobreira-Neto MA, Pena-Pereira MA, Sobreira ES, et al. Excessive fragmentary myoclonus in patients with Parkinson's disease: prevalence and clinicopolysomnographic profile. Sleep Breath 2015; 19:997-1002.

36. Raccagni C, Loscher WN, Stefani $A$, et al. Peripheral nerve function in

- patients with excessive fragmentary myoclonus during sleep. Sleep Med $2016 ; 22: 61-64$

In this study authors assessed patients with excessive fragmentary myoclonus during sleep using electrophysiological examination and found frequent peripheral nerve dysfunction, including polyneuropathy, L5 nerve root lesions, and benign fasciculations. These data suggest that despite the benign character of EFM, further diagnostic is necessary to rule out important comorbidities.

37. Allen RP, Picchietti D, Hening WA, et al. Restless legs syndrome: diagnostic criteria, special considerations, and epidemiology. A report from the restless legs syndrome diagnosis and epidemiology workshop of the National Institute of Health. Sleep Med 2003; 4:101-119. 
38. Bassetti C, Mauerhofer $D$, Mathis J, et al. Restless legs syndrome: a clinical study of 55 patients. Eur Neurol 2001; 45:67-74.

39. Montplaisir J, Boucher S, Poirier G, et al. Clinical, polysomnographic and genetic characteristics of restless legs syndrome: a study of 133 patients diagnosed with standard criteria. Mov Disord 1997; 12:61-65.

40. Baumann C, Marti I, Bassetti CL. Restless legs symptoms without periodic limb movements in sleep and without response to dopaminergic agents: a restless legs-like syndrome? Eur J Neurol 2007; 14:1369-1372.

41. Kallweit U, Siccoli $M$, Poryazova $R$, et al. Excessive daytime sleepiness in idiopathic restless legs syndrome: characteristics and evolution under dopaminergic treatment. Eur Neurol 2009; 62:276-278.

42. Collado-Seidel V, Kohnen R, Samtleben $\mathrm{W}$, et al. Clinical and biochemical findings in uremic patients with and without restless legs syndrome. Am J Kidney Dis 1998; 31:324-328.

43. Abele $M$, Burk $K$, Laccone $F$, et al. Restless legs syndrome in spinocerebellar ataxia types 1, 2, and 3. J Neurol 2001; 248:311-314.

44. Allen RP, Earley CJ. The role of iron in restless legs syndrome. Mov Disord 2007; 22 (Suppl 18):S440-S448.

45. Ondo WG, Vuong KD, Jankovic J. Exploring the relationship between Parkinson disease and restless legs syndrome. Arch Neurol 2002; 59:421-424.

46. Li X, Allen RP, Earley CJ, et al. Brain iron deficiency in idiopathic restless legs syndrome measured by quantitative magnetic susceptibility at 7 tesla. Sleep Med 2016; 22:75-82.

This is an MRI imaging study to assess differences in brain iron concentrations between RLS patients and healthy controls and their relation to severity of disease and periodic limb movement during sleep. Its novel contribution to the field is the use of quantitative magnetic susceptibility measurements to an in-vivo indicator of brain iron content.

47. Gaig C, Iranzo A, Pujo M, et al. Periodic limb movements during sleep - mimicking REM sleep behavior disorder. Sleep 2016. [Epub ahead of print] In this study, authors used polysomnographic data to describe for the first time a subtype of periodic limb movements causing dream enacting behavior in the absence of RBD diagnosis.

48. Leng $\mathrm{Y}$, Blackwell T, Stone KL, et al. Periodic limb movements in sleep are

- associated with greater cognitive decline in older men without dementia. Sleep 2016; 39:1807-1810.

In this study authors showed a relationship between PLMS and cognition suggesting greater cognitive decline associated with higher PLMS frequency.

49. Vetrugno R, Provini E, Meletti S, et al. Propriospinal myoclonus at the sleepwake transition: a new-type of parasomnia. Sleep 2001; 24:835-843.

50. Antelmi E, Provini F. Propriospinal myoclonus: the spectrum of clinical and neurophysiological phenotypes. Sleep Med Rev 2015; 22:54-63.

51. Sharpless BA. A clinician's guide to recurrent isolated sleep paralysis. Neuropsychiatr Dis Treat 2016; 12:1761-1767.

52. Passouant $P$, Billiard $M$. The evolution of narcolepsy with age. In: Guilleminault C, Dement WC, Passouant P, editors. Narcolepsy. New York: Spectrum publications Inc.; 1976. pp. 179-200.

53. Dahlitz M, Parkes JD. Sleep paralysis. Lancet 1993; 341:406-407.

54. Denis D, Poerio GL. Terror and bliss? Commonalities and distinctions between sleep paralysis, lucid dreaming, and their associations with waking life experiences. J Sleep Res 2017; 26:38-47.

55. Liskova M, Janeckova D, Kluzova Kracmarova L, et al. The occurrence and predictive factors of sleep paralysis in university students. Neuropsychiatr Dis Treat 2016; 12:2957-2962.

56. Sharpless BA, Grom JL. Isolated sleep paralysis: fear, prevention, and disruption. Behav Sleep Med 2016; 14:134-139.

57. Mellman TA, Aigbogun N, Graves RE, et al. Sleep paralysis and trauma, psychiatric symptoms and disorders in an adult African American population attending primary medical care. Depress Anxiety 2008; 25:435-440.

58. Cheyne JA. Sleep paralysis: state transition disruption and narcolepsy. In: Bassetti CME, editor. Narcolepsy and Hypersomnia. New York: Dekker; 2006. pp. 109-117.

59. Carrillo-Solano M, Leu-Semenescu S, Golmard JL, et al. Sleepiness in sleepwalking and sleep terrors: a higher sleep pressure? Sleep Med 2016; 26:54-59.

60. Zadra A, Desautels A, Petit D, et al. Somnambulism: clinical aspects and pathophysiological hypotheses. Lancet Neurol 2013; 12:285-294.

61. Bassetti CL. Sleepwalking (Somnambulism). In: Laures S, Tononi G, editors. The neurology of consciousness: cognitive neuroscience and neuropathology. London, UK: Academic Press; 2009.

62. Schenck $\mathrm{CH}$, Mahowald MW. A polysomnographically documented case of adult somnambulism with long-distance automobile driving and frequent nocturnal violence: parasomnia with continuing danger as a noninsane automatism. Sleep 1995; 18:765-772.

63. Bušková J, Piško J, Pastorek L, et al. The course and character of sleepwalking in adulthood: a clinical and polysomnographic study. Behav Sleep Med 2015; 13:169-177.

64. Lopez R, Jaussent I, Scholz S, et al. Functional impairment in adult sleepwalkers: a case-control study. Sleep 2013; 36:345-351.

65. Siclari F, Khatami R, Urbaniok F, et al. Violence in sleep. Brain 2010; 133:3494-3509.

66. Andersen ML, Poyares D, Alves RSC, et al. Sexsomnia: abnormal sexual behavior during sleep. Brain Res Rev 2007; 56:271-282.
67. Perogamvros L, Aberg K, Gex-Fabry M, et al. Increased reward-related behaviors during sleep and wakefulness in sleepwalking and idiopathic nightmares. PLoS One 2015; 10:e0134504.

68. Pedley TA, Guilleminault C. Episodic nocturnal wanderings responsive to anticonvulsant drug therapy. Ann Neurol 1977; 2:30-35.

69. Oberholzer M, Poryazova R, Bassetti CL. Sleepwalking in Parkinson's disease: a questionnaire-based survey. J Neurol 2011; 258:1261-1267.

70. Schenck CH, Milner DM, Hurwitz TD, et al. Dissociative disorders presenting as somnambulism: polysomnographic, video and clinical documentation. Dissociation 1989; 2:194-204.

71. Schenck $\mathrm{CH}$, Bundlie SR, Patterson AL, et al. Rapid eye movement sleep behavior disorder. JAMA 1987; 257:1786-1789.

72. Iranzo A, Molinuevo JL, Santamaria J, et al. Rapid-eye-movement sleep behaviour disorder as an early marker for a neurodegenerative disorder: a descriptive study. Lancet Neurol 2006; 5:572-577.

73. Postuma RB, Gagnon JF, Vendette M, et al. Quantifying the risk of neurodegenerative disease in idiopathic REM sleep behavior disorder. Neurology 2009; 72:1296-1300.

74. Knudsen S, Gammeltoft S, Jennum PJ. Rapid eye movement sleep behaviour disorder in patients with narcolepsy is associated with hypocretin-1 deficiency. Brain 2010; 133 (Pt 2):568-579.

75. Antelmi E, Pizza F, Vandi S, et al. The spectrum of REM sleep-related m episodes in children with type 1 narcolepsy. Brain 2017. [Epub ahead of print]

This study explores for the first time the presence, especially in REM stage, of motor complex behavior mimicking dream-enacting behavior in children with type 1 narcolepsy, highlighting further the cross-talk between RBD and narcolepsy.

76. Iranzo A, Molinuevo JL, Santamaria J, et al. Rapid-eye movement sleep behaviour disorder as an eraly marker for a neurodegenertaive disorder: a descriptive study. Lancet Neurol 2006; 5:572-577.

77. Poryazova R, Oberholzer M, Baumann CR, et al. REM Sleep behavior disorder in Parkinson's disease: a questionnaire-based Survey. J Clin Sleep Med 2013; 9:55-59.

78. Di Fabio N, Poryazova R, Oberholazer M, et al. Sleepwalking, REM sleep behaviour disorder and overlap parasomnia in patients with Parkinson's disease. Eur Neurol 2013; 70 (5-6):297-303.

79. Mahowald MW, Schenck CH. Status dissociatus - a perspective on states of being. Sleep $1991 ; 14: 69-79$.

80. Provini $F$, Vetrugno $R$, Pastorelli $F$, et al. Status dissociatus after surgery for tegmental ponto-mesencephalic cavernoma: a state-dipendent disorder of motor control during sleep. Mov Dis 2004; 19:719.

81. Schenck $\mathrm{CH}$, Montplaisir JY, Frauscher $\mathrm{B}$, et al. Rapid eye movement sleep behavior disorder: devising controlled active treatment studies for symptomatic and neuroprotective therapy-a consensus statement from the International Rapid Eye Movement Sleep Behavior Disorder Study Group. Sleep Med 2013; 14:795-806.

82. Panayiotopoulos $C P$, Michale $M$, Sanders $S$, et al. Benign childhood focal epilepsies: assessment of established and newly recognized syndromes. Brain 2008; 131:2264-2286.

83. Bernasconi A, Andermann F, Cendes F, et al. Nocturnal temporal lobe epilepsy. Neurology 1998; 50:1772-1777.

84. Scheffer IE, Bhatia KP, Lopes-Cendes I, et al. Autosomal dominant nocturnal frontal lobe epilepsy misdiagnosed as sleep disorder. Lancet 1995; 343:515-517.

85. Provini F, Plazzi G, Tinuper $P$, et al. Nocturnal frontal lobe epilepsy. A clinical and polygraphic overview of 100 consecutive patients. Brain 1995; 122:1017-1022.

86. Plazzi G, Provini E, Tinuper P, et al. Nocturnal frontal lobe epilepsy: clinical, video-polsyomnographic, and genetic data in 100 cases. Neurology 1998; 50:A67.

87. Tinuper $P$, Provini E, Bisulli $F$, et al. Hyperkinetic manifestations in nocturnal frontal lobe epilesy. Semeiological features and physiopathological hypothesis. Neurol Sci 2005; 26:210-214.

88. Siclari F, Nobili L, Lo Russo G, et al. Stimulus-induced, sleep-bound, focal seizures: a case report. Sleep 2011; 34:1727-1730.

89. Vetrugno R, Manconi M, Ferini-Strambi L, et al. Nocturnal eating: Sleeprelated eating disorder or night eating syndrome? A videopolysomnographic study. Sleep 2006; 29:949-954.

90. Marconi S, Scarlatti F, Rizzo G, et al. Is nocturnal eating in restless legs syndrome linked to a specific psychopathological profile? A pilot study. J Neural Transm (Vienna) 2015; 122:1563-1571.

91. Vinai $P$, Ferri R, Anelli M, et al. New data on psychological traits and sleep profiles of patients affected by nocturnal eating. Sleep Med 2015; 16:746753.

92. Thacker K, Devinsky O, Perrine $\mathrm{K}$, et al. Nonepileptic seizures during apparent sleep. Ann Neurol 1993; 33:414-418.

93. Trenkwalder $C$, Allen $R$, Hogl $B$, et al. Restless legs syndrome associated

- with major diseases: a systematic review and new concept. Neurology 2016; $86: 1336-1343$.

This article is a thorough review of the RLS with focus on associated comorbidities/ etiology.

94. Winkelmann J, Schormair B, Xiong L, et al. Genetics of restless legs - syndrome. Sleep Med 2017; 31:18-22.

This article is a thorough review of the RLS genetics. 
95. Xiong L, Montplaisir J, Desautels A, et al. Family study of restless legs syndrome in Quebec, Canada: clinical characterization of 671 familial cases. Arch Neurol 2010; 67:617-622.

96. Lemke JR, Lal D, Reinthaler EM, et al. Mutations in GRIN2A cause idiopathic focal epilepsy with rolandic spikes. Nat Genet 2013; 45:1067-1072.

97. Dauvilliers Y, Postuma RB, Ferini-Strambi L, et al. Family history of idiopathic REM behavior disorder: a multicenter case-control study. Neurology 2013; 80:2233-2235.

98. Gan-Or Z, Mirelman A, Postuma RB, et al. GBA mutations are associated with rapid eye movement sleep behavior disorder. Ann Clin Transl Neurol 2015; 2:941-945.

99. Gan-Or Z, Girard SL, Noreau A, et al. Parkinson's disease genetic loci in rapid eye movement sleep behavior disorder. J Mol Neurosci 2015; 56:617622.

100. Toffoli $M$, Dreussi $E$, Cecchin $E$, et al. SNCA $3^{\prime} U T R$ genetic variants in patients with Parkinson's disease and REM sleep behavior disorder. Neurol Sci 2017; doi: 10.1007/s10072-017-2945-2. [Epub ahead of print]

101. Gan-Or Z, Montplaisir JY, Ross JP, et al. The dementia-associated APOE epsilon 4 allele is not associated with rapid eye movement sleep behavior disorder. Neurobiol Aging 2017; 49:218.e13-218.e15.

102. Winkelman JW, Blackwell $T$, Stone $K$, et al. Genetic associations of periodic limb movements of sleep in the elderly for the MrOS sleep study. Sleep Med $2015 ; 16: 1360-1365$.

103. Denis D, French CC, Rowe R, et al. A twin and molecular genetics study of sleep paralysis and associated factors. J Sleep Res 2015; 24:438-446.

104. Chahine LM, Xie SX, Simuni T, et al. Longitudinal changes in cognition

- in early Parkinson's disease patients with REM sleep behavior disorder. Parkinsonism Relat Disord 2016; 27:102-106.

This prospective cohort study explores associations between RBD and cognition in patients with Parkinson's disease. Authors show that newly drug-naïve Parkinson's disease patients with RBD have, already at baseline, more cognitive deficits and with disease progression higher rates of cognitive decline compared to Parkinson's disease patients without RBD. These findings highlight the important prognostic value of RBD in Parkinson's disease.

105. Mollenhauer B, Zimmermann J, Sixel-Doring F, et al. Monitoring of 30 marker

-1 candidates in early Parkinson disease as progression markers. Neurology $2016 ; 87: 168-177$.

This longitudinal 2-year follow-up study investigates the progression of several candidate biomarkers over the course of Parkinson's disease. RBD may be a useful marker to monitor progression of Parkinson's disease. Daytime sleepiness progressively worsens over the course of Parkinson's disease.

106. Sixel-Doring F, Zimmermann J, Wegener $A$, et al. The evolution of REM

- sleep behavior disorder in early Parkinson disease. Sleep 2016; 39:17371742.

This observational study confirms the progressive nature of RBD in early Parkinson's disease despite initiation of dopaminergic treatment. Compared to healthy controls, initially de novo Parkinson's disease patients show a significant increase in the frequency of polysomnographic confirmed RBD in the 2-years follow-up.

107. Iranzo A, Tllosa E, Gelpi E, et al. Neurodegenerative disease status and postmortem pathology in idiopathic rapid-eye-movement sleep behaviour disorder: an observational cohort study. Lancet Neurol 2013; 12:443453.

108. Nobili L, Francione $S$, Mai $R$, et al. Surgical treatment of drug-resistant nocturnal fronta lobe epilepsy. Brain 2007; 130:561-573.

109. Mathis J, Hess CW, Bassetti C. Isolated mediotegmental lesion causing narcolepsy and rapid eye movement sleep behaviour disorder: a case evidencing a common pathway in narcolepsy and rapid eye movement sleep behaviour disorder. J Neurol Neurosurg Psychiatry 2007; 78:427-429.

110. Iranzo A, Graus F, Clover L, et al. Rapid eye movement sleep behavior disorder and potassium channel antibody-associated limbic encephalitis. Ann Neurol 2006; 59:178-181.
111. Ohayon MM, Zulley J, Guilleminault $C$, et al. Prevalence and pathologic associations of sleep paralysis in the general population. Neurology 1999; 52:1194-1200.

112. Labelle MA, Desautels $A$, Montplaisir J, et al. Psychopathologic correlates of adult sleepwalking. Sleep Med 2013; 14:1348-1355.

113. Ghanizadeh $A$. ADHD, bruxism and psychiatric disorders: does bruxism increase the chance of a comorbid psychiatric disorder in children with ADHD and their parents? Sleep Breath $2008 ; 12: 375-380$.

114. Mackie $S$, Winkelman JW. Restless legs syndrome and psychiatric disorders. Sleep Med Clin 2015; 10:351-357.xv.

115. Snitselaar MA, Smits MG, Spijker J. Prevalence of restless legs syndrome in adult ADHD and its subtypes. Behav Sleep Med 2016; 14:480-488.

116. Heim B, Djamshidian A, Heidbreder A, et al. Augmentation and impulsive

- behaviors in restless legs syndrome: coexistence or association? Neurology $2016 ; 87: 36-40$.

In the present study, authors examined RLS patients for impulsive behavior. Patients with RLS with augmentation have an almost six-fold increased risk of exhibiting impulsive behavior, suggesting that augmentation and ICDs are related and may share a common pathophysiology.

117. Falisi G, Rastelli $C$, Panti $F$, et al. Psychotropic drugs and bruxism. Expert Opin Drug Saf 2014; 13:1319-1326.

118. Uca AU, Uguz $\mathrm{F}$, Kozak $\mathrm{HH}$, et al. Antidepressant-induced sleep bruxism: prevalence, incidence, and related factors. Clin Neuropharmacol 2015; 38:227-230

119. Pressmann MR. Factors that predispose, prime and precipitate NREM parasomnias in adults: clinical and forensic implications. Sleep Med Rev 2007; $11: 5-30$.

120. Boeve BF. Pathophysiology of REM sleep behavior disorder and relevance to neurodegenerative disease. Brain 2007; 130:2770-2788.

121. Bassetti $C$, Vella $S$, Donati $F$, et al. SPECT during sleepwalking. Lancet 2000; 356:484-485.

122. Jalal B, Ramachandran VS. Sleep paralysis, the ghostly bedroom intruder' and out-of-body experiences: the role of mirror neurons. Front Hum Neurosci 2017; $11: 92$.

123. Rizzo G, Li X, Galantucci S, et al. Brain imaging and networks in restless legs syndrome. Sleep Med 2017; 31:39-48.

124. Katz PS. Neurons, networks, and moto behavior. Neuron 1996; 16:245253.

125. Tassinari CA, Rubboli G, Gardella E, et al. Central pattern generators for a common semiology in fronto-limbic seizures and in parasomnias. A neurothologic approach. Neurol Sci 2005; 26:225-232.

126. Mahowald MK, Schenck $\mathrm{CH}$. Dissociated states of wakefulness and sleep. Neurology 1992; 42 (Suppl 6):44-52.

127. Schindler K, Gast H, Bassetti $C$, et al. Hyperperfusion of anterior cingulate gyrus in a case of paroxysmal nocturnal dystonia. Neurology 2001; 57:917920 .

128. Terzaghi M, Sartori I, Tassi $L$, et al. Evidence of dissociated arousal states during NREM parasomnia from an intracerebral neurophysiological study. Sleep 2009; 32:409-412.

129. Tinuper $P$, Bisulli $F$, Provini $F$. The parasomnias: mechanisms and treatment. Epilepsia 2012; Suppl 7:12-19.

130. The International Restless Legs Syndrome Study G. Validation of the International Restless Legs Syndrome Study Group rating scale for restless legs syndrome. Sleep Med 2003; 4:121-132.

131. Manni R, Terzaghi $M$, Repetto $A$. The FLEP scale in diagnosis nocturnal frontal lobe from epilepsy, NREM and REM parasomnias: data from tertiary sleep and epilepsy unit. Epilepsia 2008; 49:1581-1585.

132. Garcia-Borreguero $D$, Ferini-Strambi L, Kohnen $R$, et al. European guidelines on management of restless legs syndrome: report of a joint task force by the European Federation of Neurological Societies, the European Neurological Society and the European Sleep Research Society. Eur J Neurol 2012; 19:1385-1396. 